\title{
Cryotherapy in Tension Headache: Analysis of the frequency of symptoms
}

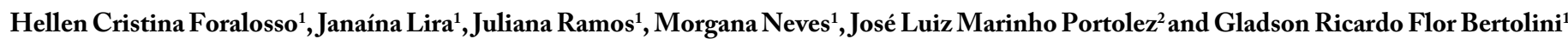

${ }^{1}$ Universidade Estadual do Oeste do Paraná - Unioeste, Brazil

${ }^{2}$ Universidade Santa Cecília - Unisanta, Brazil

\begin{abstract}
Headache is the second most frequent complaint of pain. Episodic tension-type headache is described as recurrent episodes of headache, and chronic tension-type headache necessarily requires patients to have a headache for at least 15 days per month for a period ranging from three to six months. Regarding the treatments used for tension-typy headache (TTH) are pharmacological and non-pharmacological. Among them it can mention the use of cryotherapy. However, there is a gap with respect to its effects on TTH when applied in the cervical region. Thus, the objective of the present study was to determiny the action of cryotherapy on characteristics of the frequency of pain in TTH in women, through a headache diary. Methods: 14 women volunteers were randomized into two groups, group 1 control (GI) and group 2 cryotherapy (GII). It was used a headache diary (intensity of pain, a moment of pain, characteristic of pain and associated symptoms). Results: the treated group showed a reduction for the pain intensity and changed in pain characteristics. Conclusion: The findings indicate a decrease in the frequency of pain, especially pressure pain throughout the period, with the use of cryotherapy in the cervical region.
\end{abstract}

\section{Introduction}

According to the World Health Organization (WHO), headache is the second most frequent complaint of pain. It is estimated that more than half the world's population has already had symptoms of some type of headache at some stage of life [1]. This can be defined as any pain referred to in the cephalic segment, classified as primary or secondary. The primary ones are characterized by the absence of anatomopathological abnormalities and are not due to specific organic diseases of intracranial or systemic origin [2].

Episodic tension-type headache (ETTH) is defined as recurrent episodes of headache, being a non-pulsatile continuous character of pain referred to as pressure or tightness. Its intensity can range from a mild to moderate degree, its location is variable, and may involve frontal, temporal occipital and parietal regions, isolated or combined, and may change location during a crisis. Chronic tension-type headache (CTTH) necessarily requires patients to have a headache for at least 15 days per month for a period ranging from three to six months [3-6].

With the intensification of emotional tension, levels of circulating catecholamines increase, which in turn act by resulting in contraction of muscle fibers leading to tissue ischemia and pain. Thus, anxiety, depression and stress can be caused by headache crises [7,8]. Regarding the treatments used for TTH are pharmacological (analgesic, antiinflammatory and antidepressant) and non-pharmacological, among them it can mention the use of biofeedback, cognitive psychotherapy, acupuncture, osteopathy, and physiotherapeutic resources such as manual therapy and electrothermotherapy $[4,9]$.

Cryotherapy is a therapeutic resource that presents actions on the vascular, musculoskeletal and nervous system, with effects on the decrease of muscular spasm, improvement of the range of joint movement, relaxation of the muscular fibers and interference in the generation of muscle strength. The cooling of the site is expected to result in local and systemic responses, such as vasoconstriction, decreased cellular metabolism, with lower oxygen consumption [1013]. However, there is a gap with respect to its effects on TTH when applied in the cervical region, since the study found using this modality for tension headache used cryotherapy in the frontal region [14]. Thus, the objective of the present study was to verify the action of cryotherapy on characteristics of the frequency of pain in TTH in women, through a headache diary.

\section{Materials and Methods}

A clinical trial, where the sample was selected for convenience and later randomized into two groups, group 1 control (GI) and group 2 cryotherapy (GII). The total sample consisted of 14 women volunteers, with a mean age of $22.36 \pm 1.15$ years, weight of $57.21 \pm 8.05 \mathrm{~kg}$, height $1.65 \pm 0.05 \mathrm{~m}$, BMI $20.84 \pm 2.33 \mathrm{~kg} / \mathrm{m}^{2}$. The study was carried out at the Centro de Reabilitação Física (CRF) of the Universidade Estadual do Oeste do Paraná - UNIOESTE, with prior approval by the Research Ethics Committee of the institution $(2,787,792)$. As inclusion criteria, complaints of tension-type headache in women were established; the exclusion criteria were: history of cranioencephalic trauma, neurological symptoms associated with headache, diagnosis of headache other than tension, sequelae and/or neurological diseases, undergoing analgesic drug treatment, allergy to cold or pregnant women.

After the signing of the Informed Consent Term, they were evaluated from a headache diary, which was delivered from the first intervention, in which they performed daily notes for four weeks on the characteristics of the TTH episodes. The diary was divided into

${ }^{\star}$ Correspondence to: Gladson Ricardo Flor Bertolini, Universitaria St. 2069, Cascavel, Paraná, Brazil, E-mail: gladson_ricardo@yahoo.com.br

Received: December 02, 2019; Accepted: December 20, 2019; Published: December 23, 2019 
Pain intensity

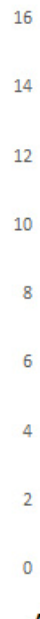

A

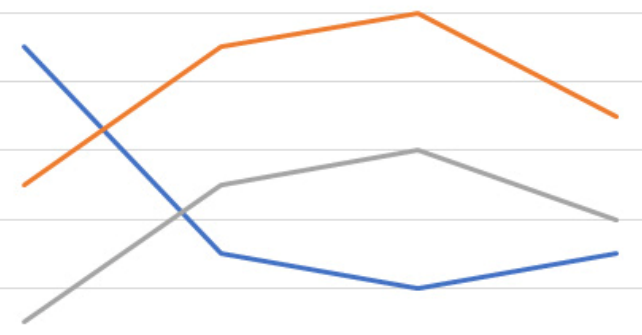

Pain moment

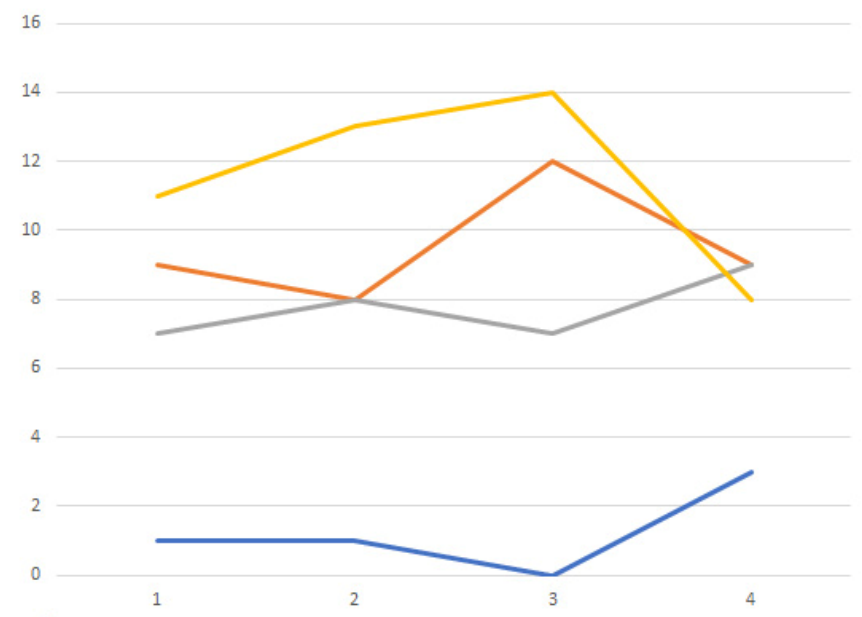

C

$$
\text { —Dawn —Morning —Evening — Night }
$$

Pain characteristic

25
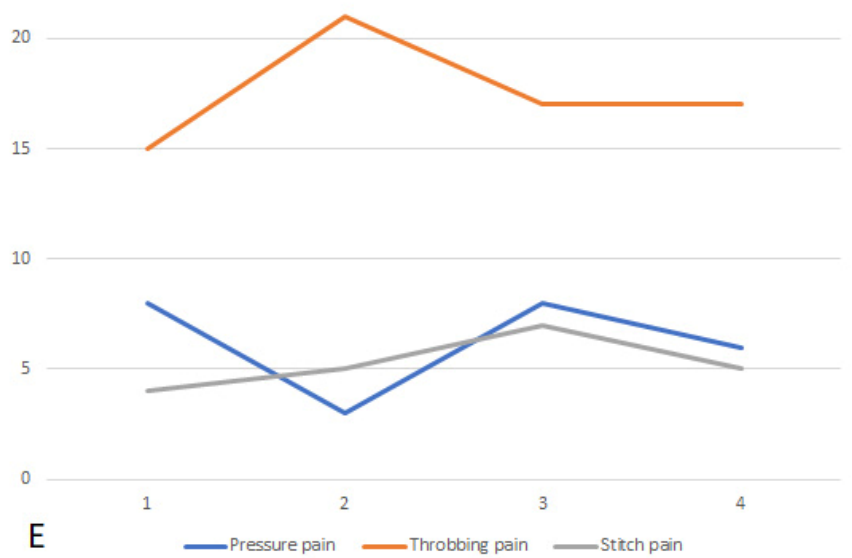

Pain intensity

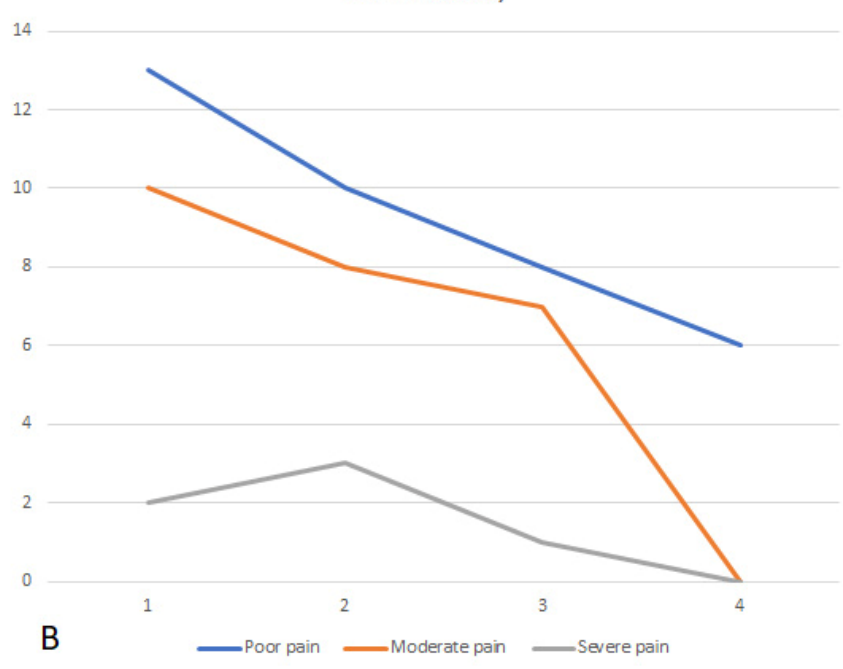

Pain monent

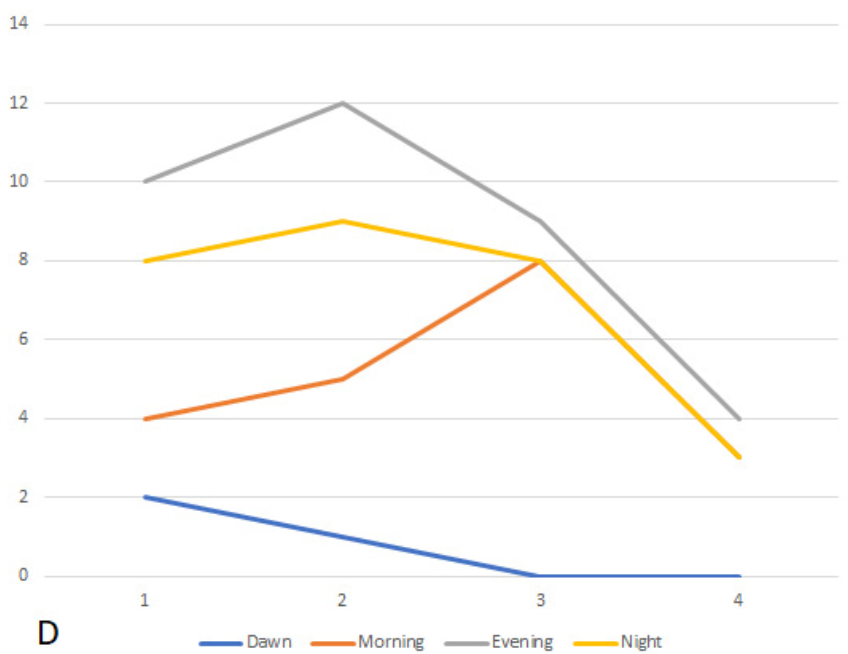

Pain characteristic

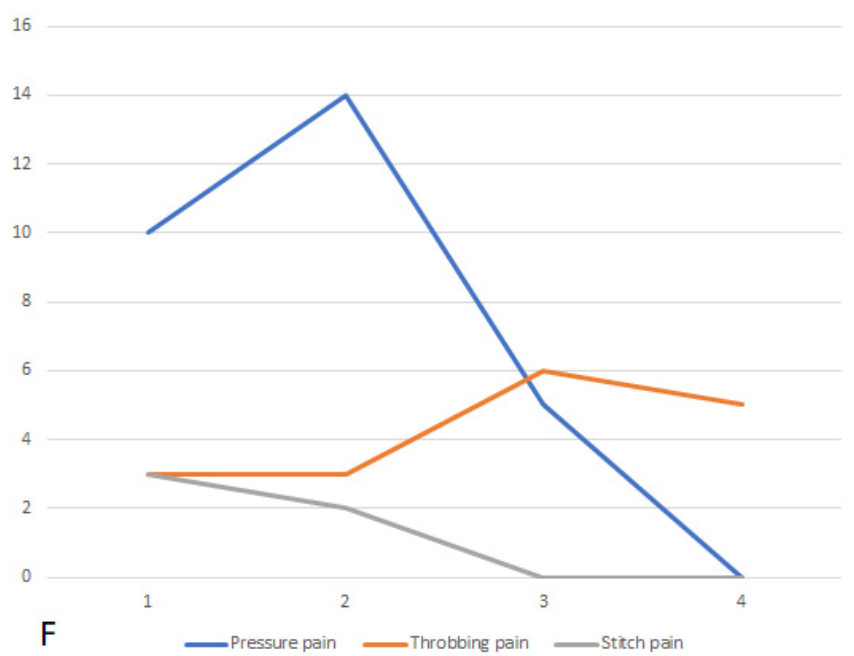




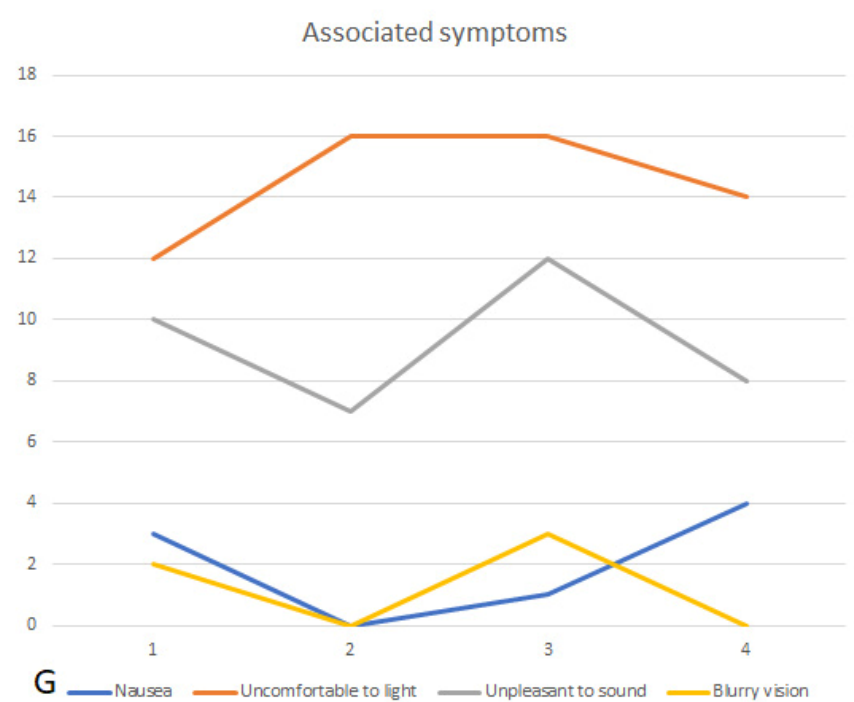

Loss of sleep

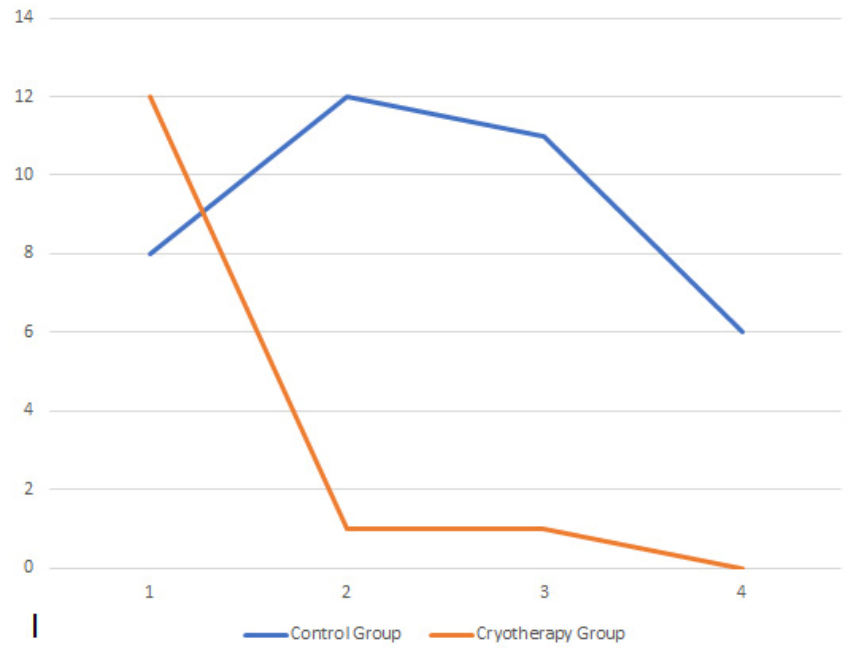

Associated symptoms

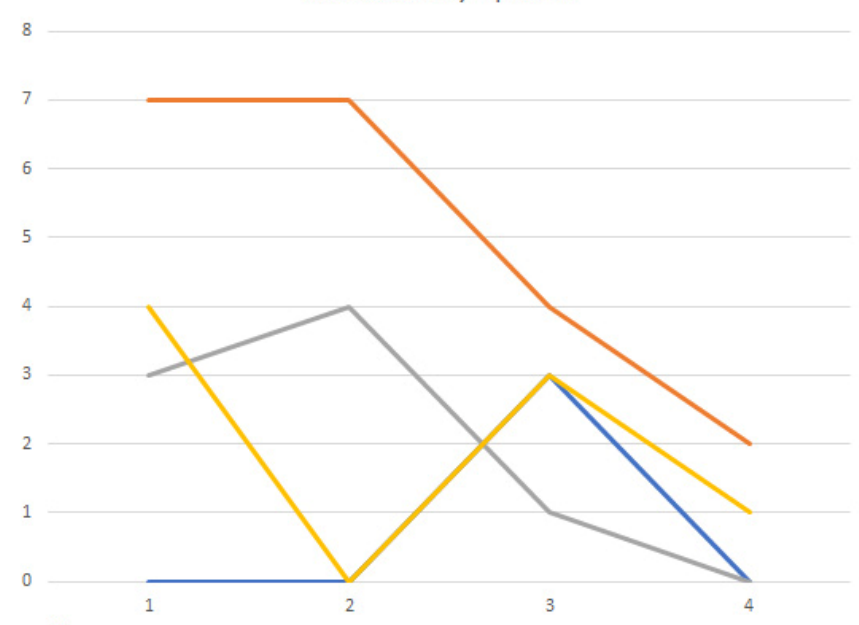

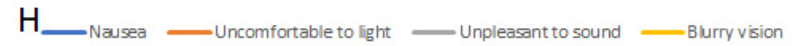

Use of medication

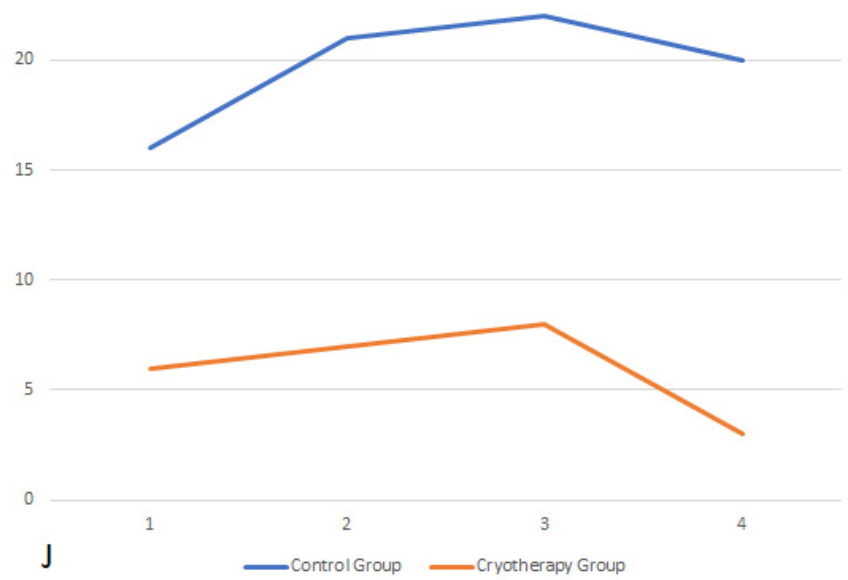

Figure 1. A- graphical representation for painful frequency in the control group (GI) and B - for the cryotherapy group (GII). C and D - the moment of pain for GI and GII, respectively. E and $\mathrm{F}$ - pain characteristics for GI and GII, respectively. G and H - associated symptoms for GI and GII, respectively. I - changes in sleep for both groups. J - frequency of medication use

four areas: pain intensity (weak, moderate or strong), pain moment (morning, morning, afternoon or evening), characteristic of pain (pressure pain, throbbing pain and / or pain in stitches) and associated symptoms (nausea / vomiting, light or uneasy sound, blurred vision), as well as questioning medication use and sleep impairment; for each variable was noted whether or not there was daily presence.

The interventions were applied in eight therapies, twice a week, with 15 min of cryotherapy applied to the posterior neck musculature in GII using a plastic bag with $1 \mathrm{~kg}$ of crushed ice. In the control group (GI) there was no therapy, but monitoring by the headache diary.

Data were analyzed using the Bioestat 5.0 program, using the Chi-square test Partition, with a significance level of $5 \%(\mathrm{p}<0.05)$. For the variables intensity of pain, moment of pain, characteristic of pain and associated symptoms, a comparison was made within the group (between weeks) and between the two groups; for drug use and sleep impairment, comparisons occurred only between groups.

\section{Results}

In the weekly analysis, for GI, there were no significant differences for any of the variables over the 4 weeks (pain intensity $-p=0.3757$, pain moment - $\mathrm{p}=0.7003$, pain characteristic - $\mathrm{p}=0.6511$, and associated symptoms $-\mathrm{p}=0.2465$ ) (Figure $1 \mathrm{ACEG}$ ). The treated group (GII) obtained significant results for pain intensity $(\mathrm{p}=0.0272)$ and pain characteristic ( $\mathrm{p}=0.0012)$ when comparing the first two weeks with the third week; in relation to the moment of pain there were no differences $(\mathrm{p}=0.8486)$; already for the symptoms associated with reduction occurred for the fourth week compared to the first two only for the symptoms of nausea and light nuisance $(\mathrm{p}=0.0050)$ (Figure $1 \mathrm{BDFH})$.

In the comparison between groups regarding pain intensity, there were no differences in the first $(\mathrm{p}=0.5317)$, nor in the second week $(\mathrm{p}=0.11712)$, but this occurred in the third $(\mathrm{p}=0.0427)$ and fourth week $(\mathrm{p}=0.0045)$. For the moment of pain, there were not any differences in the first $(\mathrm{p}=0.3964)$, second $(\mathrm{p}=0.5585)$, third $(\mathrm{p}=0.4463)$ or fourth weeks $(p=0.7454)$. For the pain characteristic, there were no differences 
for the first $(p=0.0513)$, third $(p=0.1701)$ or fourth weeks $(p=0.2292)$, only for the second one $(\mathrm{p}<0.0001)$. Difference between pressure type pain and throbbing. For the associated symptoms there were no differences in the first ( $\mathrm{p}=0.1613$ ) and second weeks $(\mathrm{p}=0.7296)$, but for the third there were differences between nausea and light annoyance $(p=0.0231)$, and for fourth week there were differences between the first variables with haze in the eyes $(p=0.0175)$. In the first three weeks there was sleep impairment $(\mathrm{p}=0.0005)$, but there was no relation to medication use $(\mathrm{p}=0.6185)$ (Figure 1I-1J).

\section{Discussion}

The present study addressed the use of cryotherapy in individuals with OST, analyzing the temporal aspect of symptoms related to pain among others. A headache diary was used for this purpose, an instrument that according Wink and Cartana [15] is a self-registration that characterizes the pain, being recommended for any type of pain without distinction. In the present study, the volunteers recorded the intensity of their pain, graduated in poor, moderate and severe, and in this variable the control group did not present variations between the weeks, whereas the treated group showed reduction for the three levels of intensity analyzed; in the comparison between the groups there was reduction of the three levels for the third and fourth weeks for the treated group.

Cryotherapy is a useful modality in the reduction of muscle spasms, edema, inflammation and therefore, both directly and indirectly, there is a possibility of pain reduction, since it can decrease pain-spasmpain cycle, pressure on free nerve endings (reduction of edema) and algogenic inflammatory products, as well as reduction of nerve conductivity [16-21]. With regard to the pain characteristic, it can also be observed that the pressure pain was reduced over the weeks, this fact may have occurred due to the decrease in the metabolic activity and decrease of the spasm of the cervical musculature $[16,19,20,22]$.

Martini, et al. [23] presented a case study in which a patient with migraine and von Willebrand disease type III made use of cryostimulation at auriculopuncture points, in addition to acupuncture points on the body. They report promising results in patients with bleeding tendencies. Another study that used cryotherapy as a treatment for migraine was Sprouse-Blum, et al. [24], with the purpose of producing cooling in intracranial vessels, report that there was reduction of pain for such patients. Similar to that observed by Ucler, et al. [25], who used a form of capillary gel for temperature reduction and reported that migraine pain was reduced in some patients.

Meng, et al. [14] used cryotherapy for tension headache over 4 weeks, used ice packs (with and without a temperature reducer) applied to the frontal region, with an unlimited number of sessions, and observed that the amount of analgesic used was reduced. In the present study, no reduction in the frequency of analgesic use was observed, but the use of cryotherapy in the cervical region produced an improvement in the sleep of the volunteers, besides a slight reduction in some associated symptoms. Several limitations may be mentioned in the present study, such as the absence of analysis of pain intensity, or electromyographic analysis of the cervical muscles, and a reduced number of samples, and these are suggestions for future studies.

\section{Conclusion}

The findings indicate a decrease in the frequency of pain, especially pressure pain throughout the period, with the use of cryotherapy in the cervical region.

\section{References}

1. Correia LL, Linhares MBM (2014) Enxaqueca e estresse em mulheres no contexto da atenção primária. Psicol Teor e Pesqui 30: 145-152.
2. Göbel H (2001) Classification of headaches. Cephalalgia 21: 770-773. [Crossref]

3. Santos-Lasaosa S, Vinueza-Buitrón PR, Velázquez-Benito A, Iñíguez-Martínez C, Larrodé-Pellicer P, et al (2016) Estudio de concordancia diagnóstica en cefalea entre neurología y atención primaria. Rev Neurol 62: 549-554.

4. May A (2018) Hints on diagnosing and treating headache. Dtsch Arztebl Int 115: 299-308.

5. Lipchik GL, Holroyd KA, France CR, Kvaal SA, Segal D, et al. (1996) Central and peripheral mechanisms in chronic tension-type headache. Pain 64: 467-475.

6. Matta AP da C, Moreira Filho PF (2006) Cefaléia do tipo tensional episódica: Avaliação clínica de 50 pacientes. Arq Neuropsiquiatr 64: 95-99.

7. Bernardi MT, Bussadori SK, Fernandes KPS, Biasotto-Gonzalez DA (2008) Correlação entre estresse e cefaléia tensional / Correlation between stress and tensiontype headache. Fisioter em Mov 21: 87-93.

8. Gaßmann J, Barke A, van Gessel H, Kröner-Herwig B (2012) Sex-specific predictor analyses for the incidence of recurrent headaches in German schoolchildren. Psychosoc Med 9: Doc03. [Crossref]

9. Flores AMN, Costa Junior ÁL (2004) O manejo psicológico da dor de cabeça tensional Psicol ciência e profissão 24: 24-33.

10. Guirro R, Abib C, Máximo C (1999) The physiological effects of cryotherapy: a review. Rev Fisioter da Univ São Paulo 6: 164-170.

11. Rêgo AS, Ferreira AIC, Ferreira CHC, Salgado FHS, Pinheiro HKS, et al. (2014) Efeitos fisiológicos da crioterapia: uma revisão de literatura. Rev Bras Prescrição e Fisiol do Exerc 8: 371

12. Felice TD, Santana LR (2009) Recursos fisioterapêuticos (crioterapia e termoterapia) na espasticidade: revisão de literatura. Rev Neurocienc 17: 57-62.

13. Allison SC, Abraham LD (2001) Sensitivity of qualitative and quantitative spasticity measures to clinical treatment with cryotherapy. Int J Rehabil Res 24: 15-24.

14. Meng WJ, Jo SY, Lee SH, Kim NH (2018) Modification of therapeutic temperature range in cryotherapy could improve clinical efficacy in tension type headache. $J$ Back Musculoskelet Rehabil 31: 577-581. [Crossref]

15. Wink S, Cartana M do HF (2007) Promovendo o autocuidado a pacientes com cefaléia por meio da perspectiva oriental de saúde. Rev Bras Enferm 60: 225-228.

16. Kowal M (1983) Review of physiological effects of cryotherapy. J Orthop Sports Phys Ther 5: 66-73. [Crossref]

17. Hsu M, Stevenson FF (2014) Reduction in muscular motility by selective focused cold therapy: A preclinical study. J Neural Transm 121: 15-20. [Crossref]

18. Herrera E, Sandoval MC, Camargo DM, Salvini TF (2011) Effect of walking and resting after three cryotherapy modalities on the recovery of sensory and motor nerve conduction velocity in healthy subjects. Brazilian J Phys Ther 15: 233-240.

19. Ernst E, Fialka V (1994) Ice freezes pain? A review of the clinical effectiveness of analgesic cold therapy. J Pain Symptom Manage 9: 56-59.

20. Chesterton LS, Foster NE, Ross L (2002) Skin temperature response to cryotherapy Arch Phys Med Rehabil 83: 543-549.

21. Algafly AA, George KP (2007) The effect of cryotherapy on nerve conduction velocity, pain threshold and pain tolerance. Br J Sports Med 41: 365-369.

22. Denton A, Bunn L, Hough A, Bugmann G, Marsden J (2016) Superficial warming and cooling of the leg affects walking speed and neuromuscular impairments in people with spastic paraparesis. Ann Phys Rehabil Med 59: 326-332. [Crossref]

23. Martini A, Schweiger V, Giuffrida A, Gandini G, Aprili G, et al. (2014) Acupuncture and auricular cryotherapy for chronic headache in a patient with type III von Willebrand disease. Acupunct Med 32: 432-434. [Crossref]

24. Sprouse-Blum AS, Gabriel AK, Brown JP, Yee MH (2013) Randomized controlled trial: targeted neck cooling in the treatment of the migraine patient. Hawaii J Med Public Heal 72: 237-241.

25. Ucler S, Coskun O, Inan LE, Kanatli Y (2006) Cold therapy in migraine patients: openlabel, non-controlled, pilot study. Evidence-based Complement Altern Med 3: 489-493. [Crossref]

Copyright: (C2019 Foralosso HC. This is an open-access article distributed under the terms of the Creative Commons Attribution License, which permits unrestricted use, distribution, and reproduction in any medium, provided the original author and source are credited. 